\title{
POLICIES AND PRACTICE IN THE BELGIUM FRENCH COMMUNITY WITH RESPECT TO COMPUTERS IN EDUCATION ${ }^{1}$
}

\begin{abstract}
The education authorities in the Belgium French Community have been cautious to avoid waste and wary of prematurely rushing the diffusion of the new information technologies. However, many initiatives have been taken at local levels with recommendations and support from centralized levels. Three types of organizing authorities oversee the educational system of the French Community. The structure of the system and the more general developments in the educational uses of computers are described first. Policy and practices under the specific organizing authorities are then reviewed in turn. All discussion refers only to the period up until 1994.
\end{abstract}

Created in 1830, Belgium became a federal state in 1990. It is divided simultaneously into three regions and three communities. The three regions, the Flemish, Walloon, and Brussels, are geographically separable and have economical powers. The Flemish part of the country borders the Netherlands; the Walloon region borders France; and Brussels, near to the Walloon region but within the Flemish region, is an officially bilingual city. Cultural powers, including the control of education, belong to the three communities of Belgium. They correspond to the three different language-speaking groups of the country: the Dutch-speaking people (located primarily in the Flemish region), a group of German-speaking people (mostly located in a small area near the German border), and the French-speaking people (who live primarily in the Walloon region). The educational system of the latter, French-speaking community is the topic of this article.

\section{The Educational System}

The Belgium French Community has two ministers of education, one for the elementary and secondary school levels and another for post-secondary

1 This report was prepared in 1994. Its realisation owes thanks to the participation of the Inspectors Cambier, Denis, Desir, Hannon, Huberty Mathot, Mossiat, Simon, and Verlove. 
education including the universities. Instruction is compulsory until 18 years of age, whereas school is not--that is, parents can claim that they teach their own children at home, but they have to be able to prove that they do. The law guarantees to parents the liberty of choice between schools, and it guarantees the right of organizing education to associations which can be financially supported by public money provided they fulfill a series of very strict conditions.

\section{The Organizing Authorities}

Actually, three types of organizing authorities exist in the educational system; and each to some degree operates at a network level. For example, the Central Public Authority acts as a network for the entire Belgium French Community. Local public authorities, such as provinces, cities, towns, and villages, have also grouped into a network named the Permanent Centre for Official Neutral Subsidiated Education and referred to as CPEONS. The free school boards, mainly Catholic and constituted by private associations of individuals, are essentially formed on the basis of philosophical and religious considerations. And the Catholic schools authorities as well have common institutions (National Secretariat of Catholic Schools, 1989) in addition to other specific network groups. All three of these organizing authorities, central, local, and free, receive funding from the Community, enough to pay $100 \%$ of the expenditures for teachers and various other ratios for the costs related to school buildings according to the nature of the organizing authority.

\section{School Levels}

The four school levels which exist currently are named at the top of the system chart in Figure 1. As the chart shows, compulsory education comprises the primary and secondary levels while the superior level refers to postsecondary education. Primary level together with preschool, for children from 3 to 5 , may be referred to as fundamental education. Some schools at the fundamental level contain a cycle encompassing about 60 children from 5 to 8 years of age with 3 teachers assigned to the group, 2 primary school teachers and one kindergarten teacher. This arrangement allows children to pass coolly from one school level to the other. 


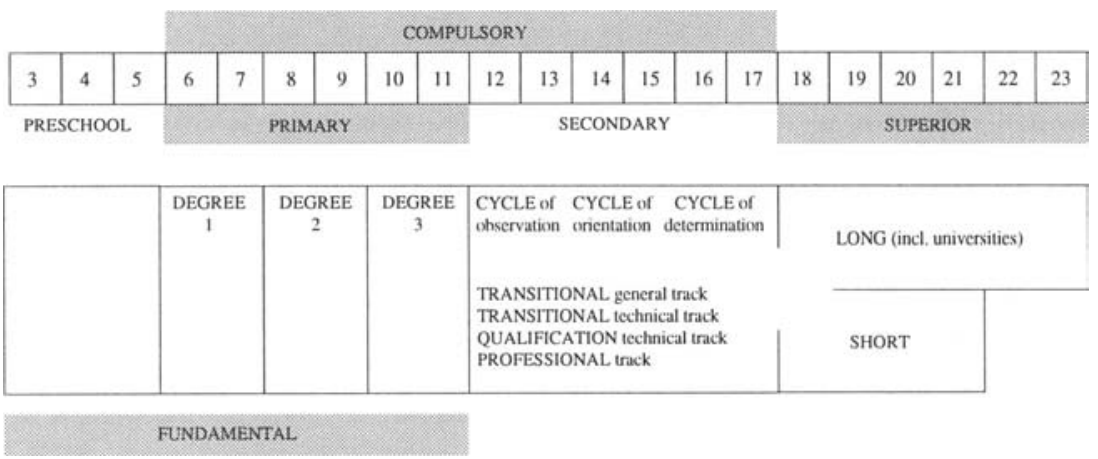

Figure 1. The Education System in the Belgium French Community.

Primary education contains three 2-year cycles (labeled Degrees 1, 2, and 3 in the diagram), and each teacher typically has 20 to 30 pupils in his or her class. But certain courses like physical education and religion are given by specialized teachers. The secondary level, too, consists of three 2-year cycles with each successive cycle having a different focus. Between the ages of 12 and 17 or 18 , students in secondary schools move through 2-year periods of observation, orientation, and determination, respectively. Since 1994, it has no longer been possible to repeat a first year of any cycle; passing to the second year is automatic.

The superior level of education includes university ( 2 years undergraduate and 2 or 3 years post-graduate) and non-university higher education, often called Graduats (without an "e"), of the short type and the long type. The difference between the short and long types is the amount of time they take, 2 to 3 years in the first case, 4 to 5 years in the last. The Belgium French Community has 9 universities, three of which have the full range of faculties, the Free University of Brussels, the Catholic University of Louvain-LaNeuve, and the Community University of Liège. Table 1 lists the total number of students in each level of the system and displays the percentage breakdown of the pupils for each organizing authority. 
Table 1. Number of Students at Each School Level in 1992 and Percent Distribution by Organizing Authority

\begin{tabular}{llccc}
\hline & $\begin{array}{l}\text { Number } \\
\text { of }\end{array}$ & \multicolumn{3}{c}{ Percent by Organizing Authority } \\
\cline { 3 - 5 } $\begin{array}{l}\text { School } \\
\text { Level }\end{array}$ & 162,645 & $\begin{array}{l}\text { French } \\
\text { Community }\end{array}$ & $\begin{array}{l}\text { Local } \\
\text { Authorities }\end{array}$ & $\begin{array}{l}\text { Free } \\
\text { (Catholic) }\end{array}$ \\
\hline Preschool & 9.1 & 50.3 & 40.6 \\
Primary & 314,027 & 11.7 & 43.3 & 45.0 \\
Secondary & 347,460 & 26.8 & 18.5 & 54.7 \\
Superior & & & & - \\
University & 59,167 & 28.4 & 30.4 & 71.6 \\
Non-university & 55,982 & 19.2 & 31.8 & 40.4 \\
Total & 939,281 & 18.4 & & 49.8 \\
\hline
\end{tabular}

Note: Of the university students in free schools, about $69 \%$ are Catholic and $31 \%$ are "free examinists".

Source: Ministry of Education (1993), Statistics for 1992. Ministry of Education, Research and Training, Brussels.

\section{Secondary Tracks}

Figure 1 devotes four lines to identifying some of the track alternatives at the secondary school level. In fact, five tracks exist and are organized in parallel. But neither the apprenticeship track, where pupils spend half of their time in school and half in a work setting nor the artistic track, are represented in the figure. The transitional general track is devoted to readying students for higher education. The technical track takes two forms. Like the general track, the transitional technical track also has possibilities that allow students to continue in higher education. The qualification technical track prepares students to general domains of competencies (in mechanical or electrical domains, for instance) and various levels of qualification. Finally, the professional track, the most vocational, prepares students to specific jobs, examples of which might be brick layers, carpenters, or drill machine operators. 


\section{Teachers Initial Training}

Preschool and elementary school teachers must acquire 3 years of training in teachers colleges called Higher Pedagogic Training Institutes (previously referred to as Ecoles Normales). Teachers for the 3 first years of the secondary level are trained in régendats, another section of the Higher Pedagogic Training Institutes. This training, also of 3 years' length, may either be oriented toward French-history-civics or modern foreign languages or science-mathematics or physical education. Teachers for the last 3 years of secondary level are trained at university in a structure called "aggregation for the higher secondary school level." Heretofore, that training has lasted half a year, but a project is in process to transform it into a full year.

Currently, each pupil has several different teachers over the course of his or her time in secondary education, usually from 6 to 12 . In part, this is because numerous specialty teachers teach in more than one secondary school. For example, a chemistry teacher could be teaching chemistry in two or three secondary schools. But a trend has been emerging to request more flexibility from teachers in the form of asking them to be able to teach other contents connected to their specialties. Such a plan should stabilize a person in a single school. In other words, a chemist could teach physics and biology in the same school as he or she teaches chemistry.

\section{Inspectors' Roles}

Inspectors in the educational system have two distinct roles, an administrative one and a pedagogical one. The former consists in checking the conformity to regulations among subsidiated institutions. The pedagogical role has two separate aspects. Its evaluative aspect involves making reports on the teaching capacities of new professors and recommending dismissals if necessary. The second aspect, as an impetus or impulse to improvement, is represented by the inspectors' efforts to invent programs, to revisit them, to promote new pedagogic ideas, and to conceive the continuous training of teachers. ${ }^{2}$

2 Non-Belgium-French Community schools have to submit proofs (such as diaries or notebooks) that they have satisfied the Community's requirements to a confirmation body (the Homologation Commission). 


\section{General Developments in the Educational Use of the New Information Technologies}

The education authorities in the Belgium French Community have always been open to using new information technologies (IT) in the schools but have refused to rush their diffusion. Large-scale plans that could have led to important waste through inadequate and premature use of the data processing tools have been avoided. Nevertheless, the gathering and analysis of information about the educational possibilities for IT have been insured in various ways. Pilot projects were carried out concerning equipment, teachers' training, and pedagogical methods. Data has been collected on the didactic innovations permanently carried out by university departments, especially by the network named "Computers Serving Education" (Ordinateur au Service de l'Education or O.S.E.) that links the five Community universities which have an educational research department. Members of ministerial and inspection departments have regularly attended meetings organized by the European Union on the subject of educational IT, and they have visited different EU countries to assess the relevancy of new pedagogical uses. By means of the EURYCLEE network, information has been regularly exchanged among educators about IT and its applications. Finally, each organizing authority has also installed structures to provide IT support.

\section{Educational Research on IT in the Schools}

In the decade of the 1980s, IT use in the schools was an important theme of funded research, commanding about $21 \%$ of the research budget. ${ }^{3}$ Projects proposed by universities or by other bodies with a legal personality are submitted to the responsible ministers for education; and inspectors, in consultation with the General Director, form a council that suggests which of the proposed projects should be funded. The final decision issued by the ministers includes specifications of the amount of the grant that will be given to the selected project and the length of time its research will encompass. A great number of the researches concerning educational IT use included either a diffusion aspect or a development aspect and dealt with computer technology or the elaboration of a tool or even the didactic of a subject. Of

3 A number of different agencies fund the education researches carried out in the Belgium French Community. The most common sources are the Fund for Collective Fundamental Scientific Research of Ministerial Initiative, the General Directorate of the Organisation of Studies, the General Directorate of Primary Education, and the Education and Scientific Research Service. 
the 234 researches which allowed themselves to be coded in this regard, $36 \%$ showed these characteristics.

\section{The Introduction of Computers in School}

Goals. The education authorities in the Belgium French Community enumerated a set of objectives for introducing computers into the schools. Their four major goals were to make children aware of the uses for computers by including the computer culture within the school-conveyed culture; to promote computers as teaching and learning tools and a professional training tool; to introduce computers in the financial, material, and teaching management of the schools; and to enable teachers to face all of these tasks-in other words, to train them, especially through permanent training. Essentially, permanent training is defined or seen as trying to make teachers capable of using existing coursewares and of modifying the variables of such coursewares to adapt them to local circumstances. Introducing a new subject in the curricula is relatively easy to do. However, including computers in the daily teaching so that they can really serve the educational methods chosen by a teacher leads to enormous problems. Attitude problems and problems of technological mastery arise as well as problems with the elaboration of personalized teaching programs.

Efforts and difficulties. In secondary education, teachers started using domestic microcomputers as a teaching aid in their classrooms as early as 1980, and some general education secondary schools introduced a computer course as a "cultural option" in the big classes. In the basic training of teachers, a course in media and data processing was introduced in 1985. But as yet, the switch to computer-aided teaching is far from complete. For one thing, it calls for much heavier equipment than what is presently in use. A single microcomputer in any school is quickly saturated even when its potential for massive use is not developed. For another thing, the number of coursewares, most of which are foreign and translated, is insufficient. Projects to create coursewares locally in languages, geography, sciences, and other subjects do not suscitate much enthusiasm among potential publishers who see their marketing prospects as hazardous.

Current uses. One way to describe the current educational uses of the new information technologies is in terms of the degree to which they have been 
adopted in the schools. The 1989 IEA Computers in Education Study ${ }^{4}$ revealed a series of interesting features in the Belgium French Community schools (Deltour, 1990; Henry \& Deltour). In technical and professional secondary education, computers had been widely introduced as a component of the professional training (for data processing, word processing, management, digital techniques, and so on). But in spite of the important efforts that had been made, the uses of computers in teaching overall remained quite scarce. While about $50 \%$ of the elementary and more than $90 \%$ of the secondary schools reported some instructional use of computers (Pelgrum \& Plomp, 1991, p. 18), in only $1 / 3$ of the secondary schools did several teachers say that they used them "a few times a year" and "less than $10 \%$ of [the] pupils in primary schools" had used them for learning (Henry \& Deltour).

Another way to describe the current use of computers is in terms of the different roles they are playing in the schools. In the drills used to instill a thorough grasp of essential notions or to support pupils who might otherwise fail, microcomputers act as a teacher. They also act as a teacher when they allow the simulation of difficult experiments. Varying parameters in a model and studying the consequences allows students to enact their own teaching. Computers are used as a tool to access data banks, to acquire and process data, and to assist technical training. In commercial schools, they are used for office applications such as word processing and spreadsheet work. In the technical and industrial courses, they serve as aids for industrial drawing or "numerical tool boxes" and assist in the automatic generation of programs. Probably the noblest use of the computer is as a tutee, allowing students to build knowledge and to create by drawing, piloting robots, or making music. Here the computer does not program the learner. Quite the contrary.

\section{Teacher Attitudes}

The teachers surveyed for the IEA study in 1989 reported that they considered computers "important" in the modern world. They believed that information technology must be a part of the cultural background of today's citizen and that they themselves as well as their pupils must learn this new science. Teachers who considered computers as gadgets, expensive toys, or

4 All state, province, Community, and Catholic schools in elementary and secondary education, excluding special education, were surveyed by this study. At the upper secondary level, this encompassed all of the vocational schools as well as the general secondary schools; at the lower secondary level, "comprehensive vocational education" was included but vocational education (with about $23 \%$ of lower secondary students) was not (Pelgrum \& Plomp, 1991, p. 114). 
an "ephemereal fashion" were rare, as were those who feared their dehumanizing effects or their threat to people's jobs. Generally too, the teachers reported that they felt confident in their capacity to "manage with a computer" (Henry \& Deltour).

The female teachers, moreover, expressed average attitudes that differed little from those of their male colleagues. However, in actuality, the women reported using a keyboard much less than the men at both school levels, and their rates of familiarity with computers at home or at school were much lower. Also, the women teachers had less often followed any kind of retraining organized by their schools, less often used a teaching program, and less often put their pupils in contact with a computer. Thus, even though they judged computers in the same manner as their male counterparts, they less often had the wish or the occasion to use them concretely.

\section{Conferences and Publications}

Several EU summer schools dedicated to the introduction of computers in primary schools have been convened in Belgium. In 1985 and 1987, they were located at the University of Liège; in 1986 and 1988, at the University of Gent. In 1990, the Seventh International Conference on Technology and Education (ICTE) took place in Brussels, co-organized by the Universities of Liège, Gent, and Austin-Texas (Estes, Heene, \& Leclercq, 1990). ${ }^{5}$ In 1993, two NATO conferences were organized by the University of Liège, one on interactive testing (Leclercq \& Bruno, 1993) and the other on control technology in elementary schools (Denis, 1993). The 4th International Congress on Control Technology in Schools also took place in Belgium in 1993 (Denis \& Baron, 1993).

One cooperative EU project conducted in France, Belgium, and the United Kingdom focussed on the clinical observation of implementing computer use in novice primary schools (that is, in schools where computers had not been used before) and resulted in two books, one in French (Osterrieth, 1989) and one in English (Blease \& Cohen, 1990). Numerous other articles and books have been dedicated to the topic of IT use in schools (Charlier, LeBlanc, \& Pettit, 1994; Duchateau, 1992; Hardy \& Denis, 1983; Leclercq, 1987). Some include treatments of more specific topics such as computer-assisted

5 The Belgium French Community's permanent representative in the ICTE Conferences, under the direction of Dr. Martegani and Dr. Van Hove, is the University of Louvain-LaNeuve. 
instruction (Depover, 1990) or the animation of a LOGO activity (Denis, 1993).

\section{Policy and Practice Differences in the Community Schools}

The politics have varied for the different organizing authorities of the educational system. Thus, this section describes specific policies and practices in the Community schools, and the next section describes the same for the free schools. Recall from Table 1 that about half of the schools are free. Among the rest of the schools, only the Community schools have guidelines.

\section{Three Goals}

Improving secondary education. For the school network of the Belgium French Community, three general goals were set up: to improve secondary education, equal opportunities between boys and girls, and permanent teacher training. ${ }^{6}$ Detailed objectives for the first goal included gaining a better knowledge of the learning process; developing pedagogical research; developing integrated or cross-disciplinary teaching; struggling against dropout decisions by students, especially in professional education; and improving via computer networking the links the schools have to each other and to their administrative offices.

Establishing equal opportunities between boys and girls with the new information technologies has received several efforts. In 1986, an actionresearch supported by the European Union began in two schools of the Brussels area with the dual aim of demythologizing IT, especially among girls, and of making the teaching community aware of the equal opportunities problem. The actions in this project were much varied. They included handson activities, interviews, investigations, visits to companies, literature searches, conferences, and debates. Discussions based upon videos or the visits of guests were also held for pupils, sometimes with their parents. All such activities are intended to encourage the greater participation of girls in the technological education available to them.

6 Policy is coordinated at the secondary level by Inspector Verlove and at the primary level by Inspector Mossiat and General Inspector Delmelle. 
Much information on this topic can be drawn from the evaluations of university teams that have been studying educational technology in the Community schools. Sougne (1989) observed that girls do not play much in a spontaneous. manner with legos and motors--"that's a game for boys"; but they do involve themselves as much as the boys in automatization and LOGO seminars. With themes that are slightly more "culturally influenced," they also build robots as well as the boys. The findings of Peeters and Debled (1989) resulted from a survey of 900 pupils, 500 in the third to sixth grades of elementary school and 400 in the first year of secondary school. The survey asked questions about which qualities were most important and how abilities were shared or divided among men and women, what professions the pupils were considering, what activities they appreciated (for instance, machine operation, team leadership, and computer handling), and so on. Differences in perceptions were observed, regarding statistics as well as abilities, which showed discrepancies with reality. Stereotypes seem to be more persistent than facts--whereupon a need for intervention! Another divergent vision of the same reality was observed in the answers given by teachers. In response to the same, but slightly adapted questions--for example, "What do the girls in your class prefer?", the teachers suspected preferences among their students that were discrepant from the actual ones the students reported for themselves.

The needs for teachers' permanent training are evaluated by the relevant administration in concertation with the inspection department, various instructors' teams, and the Training Centre of the French Community located in Huy. While it may be recommended by an inspector or headmaster, it is not compulsory. In principle, staff permanent training for Community schools is free, but the funds set aside for this purpose, constituting $0.1 \%$ of the education budget, are largely insufficient. Moreover, because of the volunteer aspect of involvement in permanent training, it is difficult to estimate what percentage of teachers is reached by an annual program. About $5 \%$ participate every year. But among them are many who, convinced of its usefulness, volunteer for most activities and come back year after year.

A wide span of topics is offered in permanent training. Among others, they include the update of theoretical and technical knowledge, introductions to the handling of new teaching materials and new technologies, and collaboration with nonscholarly environments and the economic world. The number of inservice days, seminars, conferences, program commission meetings, and meetings about research and evaluation has grown. But that has not necessarily kept pace with the growth in needs. All of these activities aim first of all at arousing the wish among teachers to adapt to new situations. As a result, the present training shows a great flexibility. It cannot ensure in 
conjunction the improvement of every teacher in a systematic, regular, and continuous way.

The days devoted to inservice or retraining sessions focus on improving teaching skills and promoting better adaptations among teachers to the goals of renovation. As a general rule, this type of training is carried out in regional groups under the conduct of inspectors or group leaders. Inservices at the Training Centre in Huy initiate teachers to the material exhibited there and also involve discussions with concerned group leaders. Recently, the Belgium French Community was able to distribute a distance computer course for a wide audience that included teachers. ${ }^{7}$ Efforts should be made in addition to build better links between the resources for school training and the resources available in other nonscholarly environments.

\section{Acquisition of Equipment}

The equipment configuration recommended for the schoolyear 1989-90 came from a leaflet issued in 1988 by the Education Head Office of the Belgium French Community schools. At that time, it was suggested that secondary, elementary, and special education schools acquire PC-XTs. Since then, a commission made up of computer specialists and delegates from the different head offices of the Ministry of Education prepared a new technical document to describe the desired equipment. Now the basic, recommended configuration consists of an AT microcomputer processor $80386 \mathrm{SX}$ with 4 megabytes internal memory, a $40 \mathrm{M}$ hard disk, and a video display. Establishments that expect to need greater speed and calculation power--for example, to link workbenches to a network--will prefer the following configuration: an AT $80386 \mathrm{DX}$ with a higher clock frequency of $25 \mathrm{MHz}$ and possibly a mathematics 80387 coprocessor. If schools wish to acquire other types of equipment, they must attend to a series of listed criteria, among which are the possibilities for extension and upgrading. The equipment recommended for administrative use is almost identical, except that it should allow in addition connection via telephone and modem to computers from the Education Department's Information Processing Centre.

The organizing authority has tried to use the equipment existing in the schools in the best manner. Hence, it has carried out equipment distribution according to pedagogical criteria. Considerations include the schools' populations and stocklists of their existing equipment, the teachers' levels and

7 The Community created a distance education service in 1959. By 1989, 200 courses and 1000 students were involved (Duchesne, 1991). 
nature of training, the subjects involved, the nature of proposed projects (excluding management projects), and the present uses of existing equipment.

\section{The Present Situation in the Community's Schools}

Elementary level. About $65 \%$ of the schools are currently equipped with at least one computer. One of the Community's inspectors is delegated by his or her peers as the main delegate for data processing orientation. The decisions and opinions of a team of inspectors that meets regularly are summarized and distributed in a monthly paper, Inspecto News. Elementary school head teachers are all kept informed in a systematic manner, and training and information is given out freely to every school every three months. The priority now goes to using word processors and programs that allow the administrative and pedagogical management of projects. School initiatives, submitted with pedagogical justifications, are chosen by the inspectors according to the evolution in their districts. Every pedagogical project that is undertaken receives technical assistance from the team of computer counselors.

Software is promoted in accordance with the general plan decided upon by the inspectors' team. A group made up of the responsible inspector and three other delegates produces and modifies coursewares so they can be presented in the schools during special information days. Four software packages that allow the management of reports about teaching staff, pupils, and supplies are now available to all of the French Community's schools.

In the classroom, emphasis is laid upon the importance of teachers being present while pupils use computers because that should help bring about a certain number of changes in the teaching function and also the discovery of pupils' different attitudes toward computers. In terms of other possible IT roles, the notion of an expert teacher who would ensure all of the data processing activities is not recommended. In fact, just the contrary. However, having a resource person can be very useful.

Secondary level. Goals corresponding to many of the approaches listed in the next paragraphs were included in the compulsory school curriculum of certain sections in 1991. Generally emphasized are the simultaneous needs to obtain information on the existing technology and to accomplish staff training (of the necessary serenity) in the realm of equipment use as well as in the pedagogical reflection necessary for using it intelligently. 
In the general track, nothing is centralized; the various uses recommended for IT depend upon the decisions every inspector makes for his or her geographic area of authority. According to the disciplines involved and the existing possibilities in the business world, some inspectors have recommended using open coursewares, languages like LOGO, and a few productions of local or foreign universities (Cabri Géomètre, for instance). Others take advantage of professional programs such as word processors and spreadsheets and even use professional databases with a pedagogical perspective. These decisions have resulted in the setting up in the classroom of application programs, mechanisms for their management and exploitation, and materials to assist students and teachers in problem solving (glossaries, formula lists, and other various forms of help). Finally, communication among school teachers has been expanded thanks to electronic mail.

In technical education, emphasis is laid upon the use of programs related to computer-assisted manufacturing (for instance, SIMCAD) and upon programmable automatic piloting. Users of the new technologies in technical education systematically express multiple goals. By exploiting the new teaching equipment, they want to develop an interactive, motivating pedagogy that makes pupils active, prepared for the future, and able to use international computer units. Ideally, students would come to understand the technological vocabulary--thanks to a correct etymological approach; learn a structured approach to problem solving and a critical sense from working with concrete problems; develop skills in logical thinking, synthetic and analytic thinking, observation, and understanding; tackle fundamental concepts better by carrying out thinking and handling simultaneously; develop creativity by learning through interaction with a technological environment that favors the acquisition of basic concepts in various fields of activity; and acquire more autonomy in the learning process. Indeed, computers are seen as connected to the development of personal well-being. Combining heuristic and algorithmic methods, correctly conceptualizing fundamental technological notions, properly interpreting the structure and internal logic of computer programs, analyzing data, and communicating results are all activities related to the attainment of these goals. 


\section{Future Perspectives}

Developing trends since 1988. Teaching institutions have increasingly been granted greater independence through funds and the freedom for schools to initiate renovation projects that adequately exploit their "teaching periods capital." In other words, global amounts of funds have been granted that can be shaped by each school to fit its specific projects. Other trends that stand out include the introduction of computers in a number of subjects such as economics, mathematics, physics, history, and electricity and the development of the "computer" options as a new subject in the curriculum. New optional subjects were also set up in professional areas such as nursing, the operation of numerical command machines, office work, and management to respond to new needs in those fields. In collaboration with universities, computer-aided and other audio-visual teaching has been elaborated. Some simple and rapid programs were also created by teachers who had acquired a sufficient background. In short, the dialogue between the teaching world and the changing technological world has more or less become permanent.

Current plans. The installation of a modem is scheduled in about 20 elementary schools, and a data bank will be set up in one school as the data feeder. Every program will be accompanied by an individual document, in the form of a contract, that aids self-training and self-evaluation. For example, the data bank will include the success percentages that were observed during previous uses and for every item. At first, the subjects covered by this project will be numbers, mathematical operations, and reading. The second use of the item bank will be as a permanent mailbox for the inspectors.

To reorganize schools, a large range of technological possibilities is theoretically available. Difficulties in changing school organization come first from the non-availability in all areas of equipment that pupils can use individually. Second, a reorganization necessarily implies greater complexity in managing the classroom because it is fully acknowledged that every pupil is at a different level in every subject. Therefore, the method of projecting from the computer screen to a large surface (with electronic acetate and a retroprojector) should meet large success as it allows the implementation of certain computer pedagogical possibilities without changing the organization of the classroom. In the same manner as a teacher uses the blackboard, he or she can remain alone and facing the entire classroom. 
Changing the curriculum seems even more difficult when it often must be done over a large geographical area such as a province or an entire country. Because a great number of French Community schools are far from being well-equipped with computers, the central authority cannot impose a uniform curriculum. Too many would not be able to implement it. Only by local initiatives or in small and prosperous bodies will curriculum changes most often be observed. Moreover, in spite of the efforts of communes and of the inspection's numerous initiatives, all of the teachers are not yet retrained. They have neither had the occasion to handle a computer in the classroom yet nor been informed of the numerous pedagogical uses offered by computers. However, a demand in that direction exists, as is notably emphasized in the report of the O.S.E. Centres (Network of O.S.E. Centres, 1991).

Considering a curriculum generalization (--but when?), educators will be facing numerous studies that have evaluated the impact of the experiments to date and will probably concentrate more on the methods than on the subjects. In other words, the students may cover more material, but not merely in order to "swallow" all of it. On the contrary, the students themselves will have to exploit IT in order to include it in their school projects. In the process, they will be laying emphasis upon their own approaches, strategies, and capabilities for acquiring new knowledge in an independent manner. Overall, the core of the curriculum will probably shrink and be compensated by a greater requirement for mastery. Will individualized tutorship and systematic drilling still be tolerated side by side with hypermediatized exploration, simulation, and micro-worlds? Probably. To what extent? That is what current researches must tell us. But we can already foresee that this will depend on the age of the learners, on the subjects, and of course on the educational objectives. Since there is a tendency to "teach as taught," the initial training of teachers should help them live what they are supposed to offer to their future students.

\section{Policy and Practice Differences for the Free Subsidiated (Mainly Catholic) Schools}

\section{Strategies to Introduce IT}

It is probably not realistic to wish to form a general description of the strategies used to introduce IT into the classrooms of the free subsidiated schools. The number of local attempts, most often by teachers' initiatives, has been great and the reasons for doing so diverse. In Belgium, there has been no real debate to precede the introduction of computers into schools, whether it 
be to consider them as a new school subject or as tools for teaching and learning. As no legal steps apply for basic or secondary education, each education network has a certain freedom and could decide that there will be " $x$ " compulsory hours of computer science in the schedule of the pupils, even though such a decision would be better made in concertation. Presently, free subsidiated schools are not obligated to offer computer science courses. Nonetheless, several factors act in favor of recognizing technology's usefulness in learning. Computer hardware and software companies and program developers see an important market in the education world, within which are the isolated teachers. Some companies even specialize in the development of educational programs. And some non-computer companies, such as banks, list their existing programs and provide access to their data banks via modem.

It is presently hoped that all of the secondary pupils will either take a computer course or one of the other subject options that include computer science as a part of the course (for instance, office work). But courses with computer science components are not always available, and the existing structures do not easily allow for change. Right now a pupil could take a computer course in the first year of secondary school and pursue it for 6 years or start learning about computers 2 years later and pursue it during the following 4 years. This manner of functioning implies the problem of heterogeneity among the pupils' levels since teachers may have both beginner and experienced pupils in the same class.

\section{Structures}

At the National Federation of Secondary Catholic Education (FNESeC), a data processing department for basic education has three attributions: the link between data processing and school administration, the file "computers and pedagogy," and everything informative regarding the school equipment (both the hardware and software necessary for the pedagogical and administrative aspects). This department ensures as well the organization of the teaching of computer science as a subject.

Another body, the Reflexion Group on Computers and Education, created in 1990 and constituted of stakeholders in the Catholic School Federation, inspectors, university professors, and school teachers, is in charge of revisiting the content of computer literacy courses in secondary schools. A few years ago, the Reflexion Group sent a questionnaire to the teachers in charge of this course asking for their opinions and facts about their schools (Duchateau \& Sass, 1992). Based upon the answers it received, the group 
proposed a deep revision of the curriculum (FNESeC, 1992a, 1992b). It also organized (within the framework of the Catholic Institute for Continuous Training) work groups of teachers, inspectors, and university professors whose missions were to produce didactic examples illustrating the new principles.

\section{Equipment Funds and Acquisition}

The introduction of computers into the classroom is subordinated to a number of different factors; the education world--which is more or less the carrier, the personality of the authority in this area, local teachers' initiatives, the schools' headmasters, the inspectors, and the concertation between these actors. The non-profit association set up for the Catholic education, INFODIDAC, has been in charge since 1992 of studying the technical problems related to computerizing schools in the free schools network. It organizes the commercial operation of acquiring equipment, formulated some recommendations with regard to the kinds of hardware that should be adopted, and negotiated reference contracts with computer producers. As no budget amount is allotted in the free schools' network for the new information technologies, every school must equip itself using its own budget which comes mainly from subsidies. ${ }^{8}$ Thus, INFODIDAC suggests that school headmasters place grouped orders for hardware and software in order to purchase the items at lower cost, and it even offers appealing financing facilities to schools so as to help them purchase the IT tools they need.

Grouped purchase proposals normally concern products that will be compatible with the old machines. Windows was excluded, for instance. Schools are submitted to fashion and to outside financial influence. Because of the world market and because of the lowering of equipment prices, they are essentially equipped with compatible PCs. However, many machines in use date back to the early 1980s (Apple II, BBC, TRS 80), a time when they were used for the learning of algorithms which did not require sophisticated equipment. The number of XT and AT PCs in the 400 secondary schools were counted at 4000-5000 in the early 1990s. But these numbers should not lead to the calculation of an average. Every school does not own 10 computers!

When a new product appears, whatever be its source, the present policy of the free schools' computer department is to set up a team of inspectors and

8 The Government does, however, give out budgets now and again for the permanent training of teachers, and parts of those funds are sometimes used for IT. 
teachers to evaluate the product. The team defines its own criteria from a pedagogical point of view and evaluates the product solely from the computer point of view. Once these analyses are finished and negotiation with a distributing company has been arranged, the product can be distributed to the schools that request it.

\section{The Extent of IT Use in Schools}

In elementary schools, computer-assisted education is essentially present with the use of small drill programs, word processors, and the LOGO language. But this is true in a limited manner because of the lack of equipment in the schools and the price of coursewares. Out of 790 elementary schools, 1/3 own at least one computer, but it is often intended for administrative management. Only about 10 schools have small computer laboratories.

In secondary education, computer courses are not compulsory except in specialized sections such as computerized management, office, and economics or where a course's content includes the use of a computer. Other secondary pupils who wish to have computer courses in their programs may do so by selecting a complementary activity or course as one of their optional choices. Until the early 1990s, the most widespread computer course dealt with algorithms. But changes in priorities happen as time goes on (cf. FNESeC, 1992a, 1992b). Presently, most teachers wish to use computers in every school year and to maintain a single computer option that studies algorithms in depth only for a more specialized audience in the third cycle of secondary education. Certain areas more aware of the use of computers and for whom programs and direct applications exist (accounting, artistic sections, and so on) have already progressed in their use of IT. Requests about the possible uses of computers have begun to appear in other areas, too. Technical and professional tracks often request products because they are used in the professions for which pupils train, in the clothing profession or office work, for example.

Equal opportunities between men and women. No steps currently exist concerning equal opportunities. But because of the present widespread idea that new technologies are. "sexualized", the secondary education authorities have decided to make school headmasters aware of the problem and to suggest using computers in ways that try to erase this inequality. 


\section{The Most Successful Strategy Areas}

Administration. School microcomputers are widely used as management tools via a number of applications of interest to headmasters, secretaries, and other school staff. These applications are either the result of a centralized solution, a local solution, or one that combines the efforts of central and local actors and actions. Altogether, they contribute to creating a shared computer culture. Whereas, every school in the French Community network sends its data to a central computer which processes the data and sends it back, in free Catholic education, the centralized school authorities help to specify a management tool, and then its elaboration is entrusted to a local team. Once the tool is chosen, tested, and validated, it is distributed among the schools that wish to acquire it. Of course, solutions involving a home-made software are entirely local. The school management programs produced by INFODIDAC were developed in close collaboration with the relevant administrative authorities and are used by the majority of Catholic schools. Opinion questionnaires about these software packages (namely Prosec for secondary education, Proprim for the primary level, and Cubic) revealed a satisfaction rate of $95 \%$ with them.

Teaching computer science. In secondary and third cycle education, computer science has become a subject that is taught just like any other. Certain professional and technical areas that include data processing in their curriculum must be considered differently than the general education which offers a computer science course. Since 1983, the most frequent situation has probably been the 2-hours-per-week complementary option in the last two years of secondary school. Generally, the necessary data processing equipment is gathered in the room where the course is given or at least a room pupils may go to in the framework of their training. Most often mathematics and science teachers are responsible for the computer courses, which typically represent a joint activity with most of the efforts still being made in the main subject. Most often computer science was not included in the initial training of these teachers. They are either self-taught or had to retrain in order to acquire the necessary skills.

The main reasons that motivate the teaching of computer science are fashion, competition between schools, pressure from parents ("Computer science is the future!"), and the social myth ("Those who know computers have no problems in getting jobs!"). Yet that kind of pressure did not necessarily require the setting up of a new course. The important thing to meet the demand was simply to arrange that young people "could touch" or get to "be familiar" with computers. But the structure of secondary education 
being what it is--compartmentalized into subjects, the shortest way to "put the pupils in contact with computers" was in fact to set up a new course. The announced goals of such courses are to demythologize the computer and data processing and to help pupils to discover and handle the programs and to think about the social and cultural implications of computerization. But most of all, the goal is to train students to the algorithmic way of thinking, which mostly comes from a correct learning of programming. Beyond the information aspect of the suggested initiation to programming, the educational aspect is widely put forward. That is, programming should develop pupils' analytical and organizational capabilities, lead them to a better problem-solving methodology, and increase their capabilities for expressing themselves in a clear and rigorous manner.

Since 1992, as a consequence of the work accomplished by the Reflexion Group on Computers and Education, a new form of initiation to the use of computers and software has been suggested in the format of a course entitled Computer Sciences--A Workshop for All (FNESeC, 1992a, 1992b). The central objective of this idea is to offer to the greatest number of pupils possible a relevant and effective encounter with basic concepts about computing and to enable them to use software tools in a creative, efficient, and mind-controlled way. Pedagogical guidelines are currently being elaborated to suggest strategies for the project and give methodological advice to teachers. At last, too, an experiment with a "technico mental" activity is developing in 10 schools in which control technology (robotics) is a central part of the approach.

Computer-assisted education is easier to introduce among pupils of professional education than among those of general education, probably because the teachers in professional classes use computers more willingly. Data processing was first introduced in a structured manner at the second and third levels of professional education. More recent programs exist for general education and for (transition and qualification) technical education, but the programs for professional education were never brought up to date. Thus, although the programs exist for the second and third levels, the schools must not use them. In order to follow an alternate program, a school must write one and submit it to higher authorities for approval. At the second level, every school that wishes to use computers must write its own program. Among the teachers, mathematicians have been taught to use software like Cabri Géomètre and, in a minor way, Mathematica, and networks of users have been formed that permit exchanges of experiences and questions with particular software programs. An especially active group is in mother tongue learning where software like Elmo is extensively used. 


\section{Looking Back and Forward}

Factors for success. The success of educational IT in the free subsidiated schools depends upon three essential factors. Most obvious are the equipment and the nature of the teachers' training. The third factor is the setting up of logistic teams that can be responsible for the efficient and harmonious operation of the data processing units.

In terms of equipment, much effort must still be made, but the choices are difficult because of the fast evolution of available computer configurations. As the equipment will always evolve faster in the market than in the schools, we could find ourselves in varied classroom sceneries composed of PCs (XT or AT 286 and 386) and Macintoshes. This diversity seems less difficult to manage, however, than were the incompatibilities of the first wave of microcomputers. The users' computer culture today builds itself much more around the programs than around the equipment, and the program environments (especially user interfaces) presently tend towards uniformity. Little by little, at the same time as equipment enters the school, the differences remaining in the deeper layers of the equipment and the basic program are disappearing.

The teachers, as future users of IT, must be made aware of its importance. This enterprise is a long-range one which has to join sufficient technical mastery to reflections about and experiments with the relevance of such-andsuch programs for particular pedagogical uses. When a sufficient number of pioneers are trained in every subject, the solution will probably be that these experienced teachers ensure the training of their colleagues. Probably too, this will constitute the best guarantee of an actual appropriation of the computers by concerned teachers and for the various subjects. The moment, and the place one would choose, for this awareness to be instilled is in teachers' basic training, where most of the efforts should be concentrated.

Technical support specialties are needed because the use of IT is always accompanied by a certain number of technical problems. Sooner or later, the users, even if they became specialists with a given software program, will face problems they cannot solve such as a virus infection or how to interface with a certain printer or simply the accidental erasure of a floppy disk--or worse and not so simply, a hard disk. A reasonable solution cannot be for all users to become absolute experts in the details of DOS or distinguished connoisseurs of the repertoires' labyrinths. That would be similar to expecting all automobile drivers to become mechanics. However, none of this means that, when the time comes, a user should not be able to call quickly and on the 
spot for the help of an expert colleague. One or several experts are needed in a school for the others teachers to call upon. The role of these "computer fixers" should be officially recognized and should affect their status (by giving them training possibilities, fewer teaching hours, and so on). Relying solely on the good will and helpfulness of random others may work for a time. But over a long period of time, we condemn a great part of an innovation project's logistic--thus the project itself--if we do not recognize officially the services rendered by the teachers involved. These are a few factors to consider within the school itself if we wish to use computers harmoniously.

Some conditions for technical support must also be met outside of the school. When facing the frequent failures, often even the carelessness or incompetence of some equipment and program salespeople, schools often cannot solve the problem with their local experts. These difficulties must absolutely be submitted to an expert team whose task should be to help the serious cases of difficulty concerning application programs and basic progress. The local experts could be partially integrated to these teams and serve as an interface through their capacity to precisely describe the problems. In addition, we need a place where all of the people cited above will be able to help each other and work side by side, the "SOS-computer" team, the persons responsible for the census of the educational products in the schools, those who manage the teaching software library, the instructors, the researchers, the program conception teams, and so on.

Other issues. No means of developing educational products that will use the new technologies exist in the federation. Setting up teams to create applications for products that may be used as a development basis for teachers (hypercard, for instance) would be interesting. For the open computer-assisted education programs, groups should be set to work to fill them by creating use-scripts and learning sequences based on the various products.

The idea that everyone in secondary education should be able to access the computer lab, if one existed, is often repeated. Typically that requires modification of the social organization in the schools. Pupils of professional education have long been disfavored in this respect. An important component in the potential to modify schools' organizations has probably been the influence of data processing upon the schools' administration.

The fact that activities can now take place in schools which could not take place before sends questions back to challenge the creativity of the teachers, 
of their authorities, and of the programs. We must, however, see to it that computers do not evict existing structures and do not systematically influence the contents. As of yet, no study has been conducted on the impact or the advantages of the new technologies in education, except for the research carried out by the National Federation of Secondary Catholic Education (FNESeC) on the teaching of computer science as a subject (cf. Duchateau \& Sass, 1992). The results of its project, entitled "[The] role of the training to computer science in free Catholic secondary education," have yet to be published.

\section{Concluding Remark}

Microcomputers are not even 20 years old. Commercial programs for them are not even 10 years old. Yet one could expect that the educational uses of computers would be numerous and commonplace. Here as elsewhere, these changes will come with time. Pulling on children will not make them grow faster! And patience need not mean passivity or simple expectations but rather perseverance and stubbornness. Another trap would be to believe that the necessary conditions, the provision of hardware and software, will be sufficient. Only the teacher facing the students in a classroom can allow the union of data processing tools (and of other technological means) with the school universe. That person alone has the power of transforming the enormous potential of the new technical means into beneficial realities for teaching and for learning. A successful introduction to computer science for the students in a school is unavoidably dependent on its integration into the methodologies of the teachers. Our school system is going through a crisis as are most of the occidental educational systems, and the new information technologies, with all of their possible tools, do not provide the universal remedy. There is nevertheless a positive aspect to this first era of IT's uses in education. Many of the products developed during this time were easily integrated into the everyday practice of the teachers because the potential users had also been the creators.

\section{References}

Blease, D., \& Cohen, L. (1990). Coming to terms with computers. Service de Technologic de l'Education, Universite de Liège.

CERI. (1992). L'éducation et les Nouvelles Techniques de l'Information, Formation des enseignants et recherche: une enquête sur des projets de coopération entre universités et écoles (Education and the new information technologies, molding the teaching and research: 
A survey of cooperative projects between universities and schools). Center for Research and Innovation in Education (CERI), Paris.

Charlier, B., LeBlanc, R., \& Pettit, V. (1994). "Un EDIPO, comment ça se vit en classe?" In L'intégration de l'ordinateur à l'école. Vol. II. Des outils pour apprendre avec l'ordinateur (The integration of the computer in school, Vol II: The tools for learning with the computer), directed by P. Bordeleau. Montreal: Editions Logiques.

Deltour, N. (1990). Les ordinateurs en Education (Computers and education, Report on the IEA Study of Computers in Education in the Belgium French Community). SEDEP, Universite de Liege.

Denis, B. (Ed.) (1993). Control technology in elementary education (NATO Asi Series, Vol. 116). Heidelberg: Springer Verlag.

Denis, B., \& Baron, G. (1993). "Regards sur la robotique pédagogique" (A look at robotics pedagogy). Proceedings of the Fourth International Colloquium on Robotics Pedagogy, July 5-8. Service de Technologie de l'Education, Universite de Liege, Institut National de Recherche Pedagogique (INRP), Paris.

Depover, C. (1990). L'ordinateur Media d'enseignement (Computer media in education). Brussels: De Boeck.

Duchateau, C. (1992). "L'ordinateur et l'école. Un mariage difficile" (The computer and the school. A difficult marriage). FUNDP, 5(28):31 (Publications of CEFIS, Facultes Universitaires Notre-Dame de la Paix, Namur).

Duchateau, C., \& Sass, F. (1992). "En Belgique, où en est-on? Où va-t-on?" (In Belgium, where have we been? Where are we going?). Pp. 15-27 in Proceedings of the Third FrenchSpeaking Meeting on the Didactics of Information Processing. Sion, Paris: EPI.

Estes, N., Heene, J., \& Leclercq, D. (Eds.) (1990). New pathways to learning through educational technology (Proceedings of the Seventh International Conference on Technology and Education-ICTE, May, Brussels). Edinburgh: CEP Consultants.

EURYDICE. (1990). Structure d'enseignement et de formation initiale dans les Etats membres de la Communauté Européenne (The structure of teachers' initial training in the member states of the European Community). Commission of the European Community, Brussels.

FNESeC. (1992a). Un atelier pour tous: Perspectives (A workshop for all: Perspectives, Document 1992/0279/102/A). Information Processing, National Federation of Secondary , Catholic Education (FNESeC), Brussels.

FNESeC. (1992b). Un atelier pour tous: Programmes (A workshop for all: Programmes, Document 1992/0279/102/B). Information Processing, National Federation of Secondary Catholic Education (FNESeC), Brussels.

Hardy, J.L., \& Denis, B. (1983). Pourquoi LOGO dans un contexte éducatif? (Why LOGO in the educational context?) Labor, Brussels.

Leclercq, D. (1987). "L'ordinateur et les défis de l'apprentissage, partie no 1 " (The computer and the challenge of learning, Part 1). Horizon, 13:29-32.

Leclercq, D. (1988). "L'ordinateur et les défis de l'apprentissage, partie $\mathrm{n}^{\circ} 2$ " (The computer and the challenge of learning, Part 2). Horizon, 14:22-25.

Leclercq, D., \& Bruno, J. (Eds.) (1993). "Item banking, interactive testing and self-assessment." Colloque NATO ARW. Berlin: Springer Verlag.

Ministry of Education. (1985). Etude de la faisabilité de l'introduction de l'informatique dans l'enseignement (Feasibility study for introducing information technologies into education). Bureau of Marcel van Dijk, Ministry of Education, Research and Training, Brussels.

Ministry of Education. (1986). L'informatique dans le système éducatif (Information processing in the education system). Bureau of Marcel van Dijk, Ministry of Education, Research and Training, Brussels. 
Ministry of Education. (1990). Le mouvement éducatif en Communauté Française de Belgique (The education movement in the Belgium French Community). Ministry of Education, Research and Training, Brussels.

National Secretariate of Catholic Schools. (1989). Répertoire de l'Enseignement Catholique (Index of Catholic teaching). LICAP s.c., Rue Guimard 1, 1040 Brussels.

Network of O.S.E. Centres. (1992). Rapports d'activité (Report of activities). Ordinateur au Service de l'Education (O.S.E.) O.S.E. reports may be obtained through Dr. Boxus or Dr. Leclerq whose affiliations are shown below.

Osterrieth. (1989). L'Informatique tranquille (Be cool with IT). Collection of Pedagogy and Research, Director General of the Organisation of Studies, Brussels.

Peeters, R., \& Debled, C. (1989). Intérêt et participation des filles lors des activités scolaires liées aux Nouvelles Technologies de l'information (The interest and participation of girls since school activities joined to the new information technologies, Report on the researchaction 1988-89 of the CCE). Director General of the Organisation of Studies, Brussels.

Pelgrum, W.J., \& Plomp, Tj. (1991). The use of computers in education worldwide. Oxford: Pergamon Press

Sougne, J. (1990). "Logo Scan: A toolkit to analyse Logo programs." In New pathways to learning through educational technology (Proceedings of the Seventh International Conference on Technology and Education-ICTE, May, Brussels), edited by N. Estes, J. Heene, and D. Leclercq. Edinburgh: CEP Consultants.

Drs. Boxus and Leclercq are associated with the University of Liège, the former being the scientific secretary of the General Board of Studies and the latter being a Professor and Head of the Service de Technologie de l'Education. Dr. Duchateau is affiliated with CEFIS, Facultés Universitaires Notre-Dame de la Paix, Namur. 